\title{
TOWARDS AN INVESTIGATION ON THE DETERMINANTS FOR EFFECTIVENESS AND EFFICIENCY OF REVERSE LOGISTICS SYSTEMS (RLS)
}

\author{
Francisco Gaudêncio Mendonça Freires \\ Universidade Federal da Bahia, Brazil \\ E-mail: francisco.gaudencio@ufba.br
}

Submission: $26 / 06 / 2013$

Revision: 09/07/2013

Accept: 27/08/2013

\begin{abstract}
This article deals with the influence of economies of scale and postponement on the efficiency and effectiveness of reverse logistics systems (RLSs). In a global way, it provides an understanding of returns management and RLSs to generate knowledge of practical and theoretical character. Starting from a generic model of circular flow of materials, the system studied is positioned between the final consumer and the traditional or direct supply chain. It is a qualitative approach over two case studies carried out in Portugal and Brazil dealing with scraptires. One deals with management system while the other deals with the reverse logistics system. As conclusions, the efficiency of RLSs is aided by economies of scale. Postponement has positive effects on efficiency by increasing the system capacity reducing logistics costs which indirectly leads to economies of scale, having a positive influence on the effectiveness of RLSs. According to what has been stated in this paper, the coordination between the direct and reverse flow is a typical case of a closed circuit.
\end{abstract}

Keywords: reverse logistics systems, economies of scale, postponement 
INDEPENDENT JOURNAL OF MANAGEMENT \& PRODUCTION (IJM\&P)

http://www.ijmp.jor.br

v. 5, n. 1, October - January 2014.

ISSN: 2236-269X

DOI: 10.14807/ijmp.v5i1.106

\section{INTRODUCTION}

Business performance management was mainly financial for many years. Nowadays, however, models such as the Balanced Scorecard (BSC) are designed to monitor the implementation of the strategy outlined for the company, promoting their re-evaluation, from strategic discussions, but keeping the financial indicators and also including non-financial indicators, united in order to form a system of evaluation.

Holmberg (2000) states that companies that have succeeded in managing the performance of their supply chains thought about chain as a whole and sought results shown in the revenue growth, asset utilization and cost reduction, in other words, the strategic themes. When talking about performance management, you cannot leave aside two concepts: effectiveness and efficiency. Both are components of performance, which are addressed in different ways according to the subject or discipline to be investigated.

According to Harrington (1993) and Neely et al. (1995), the effectiveness refers to the extent to which the outputs of the processes or sub-processes reach the needs and expectations of customers. You could say that effectiveness refers to produce the 'right things'. Organizations must meet the needs of customers and then produce the appropriate product (product being a good or a service). To measure the effectiveness of an organization, one must measure the results achieved by the processes. Efficiency is an indication of how resources are used by the organization (resources are minimized and wastes are eliminated) to achieve efficacy (HARRINGTON, 1993; NEELY et al., 1995). In simple words, efficiency is doing 'things right'. Once the organization found the needs of its customers, it should produce the product/service using minimum resources possible.

Like any logistics system, the RLSs must be effective and efficient. Logistics effectiveness and efficiency can be approached from several perspectives and be related to several issues. In this section, the determinants for logistics effectiveness and efficiency will be described and discussed. The aim is to settle specific issues related to the effectiveness and efficiency of reverse logistics systems (RLSs) that will be addressed throughout this work. As logistics is a vast topic and includes a wide range of issues and aspects concerning performance management, three areas were chosen to be investigated afterwards. 
The discussion of this work is centered on two principles covered to a certain extent by the literature on logistics. The principles presented are economies of scale and the postponement, both associated with the push strategy. The two principles aim the increase of logistics effectiveness and efficiency in terms of cost reduction, increased resource utilization and customer satisfaction. Due to the descriptive and partly analytical interest of this work, we intend to answer a question:

What is the influence of economies of scale and postponement on the efficiency and effectiveness of RLSs?

Economies of scale and postponement relate to several decisions of interest to the logistics, such as variety of products, location of factories and warehouses, modularization of products and process reengineering. Both principles aim the increase of logistics effectiveness and efficiency in terms of cost reduction, increased resource utilization and customer satisfaction. Therefore, they work as determinants for logistics effectiveness and efficiency in logistics systems (direct or reverse).

The discussion throughout the paper will be based specifically on reverse logistics systems for scraptires. The choice for this type of product is due to the fact that scraptire represents a large environmental problem both within Brazil and globally and also present challenges in terms of achieving economies of scale and adoption of postponement. Case studies were conducted in Portugal and Brazil as part of the collection of data from a doctoral project. Findings related to these two principles are analyzed and the answers to the research question are presented in the form of propositions.

\section{ECONOMIES OF SCALE AND POSTPONEMENT}

Feitzinger and Lee (1997), Van Hoek et al. (1998) as well as Pagh and Cooper (1998) have approached economies of scale and postponement regarding the configuration and strategy creation for supply chains. More recently, Yang et al. (2007) states that responsiveness can be achieved through a combination of economies of scale and postponement strategies.

Both principles, economies of scale and postponement were largely related to the direct distribution of logistics systems. As the main objective of this paper is the investigation of RLSs, basically the collection and post-collection systems, it is 
DOI: 10.14807/ijmp.v5i1.106

possible to perceive the collection system as an inverted image of the distributon (Figure 1).

In general, property recovered or recycled must compete on price with virgin materials or new products (GEYER et al., 2007; GALBRETH and BLACKBURN, 2010). Thus, the reverse channel development with a focus on cost reduction becomes necessary for these prices to remain low. The possibility of achieving this reduction passes through economies of scale in steps of collecting, sorting, and especially in transportation. In order to achieve these savings, companies involved in the reverse channels should have focus on the volume of collected and processed material. In the same line of thought, Stock (1998) and Ferguson, Fleischmann and De Souza (2010) argue that economies of scale, in respect to volumes, are important for the viability of reverse logistics programs, both for an individual company and for the partnership between businesses.

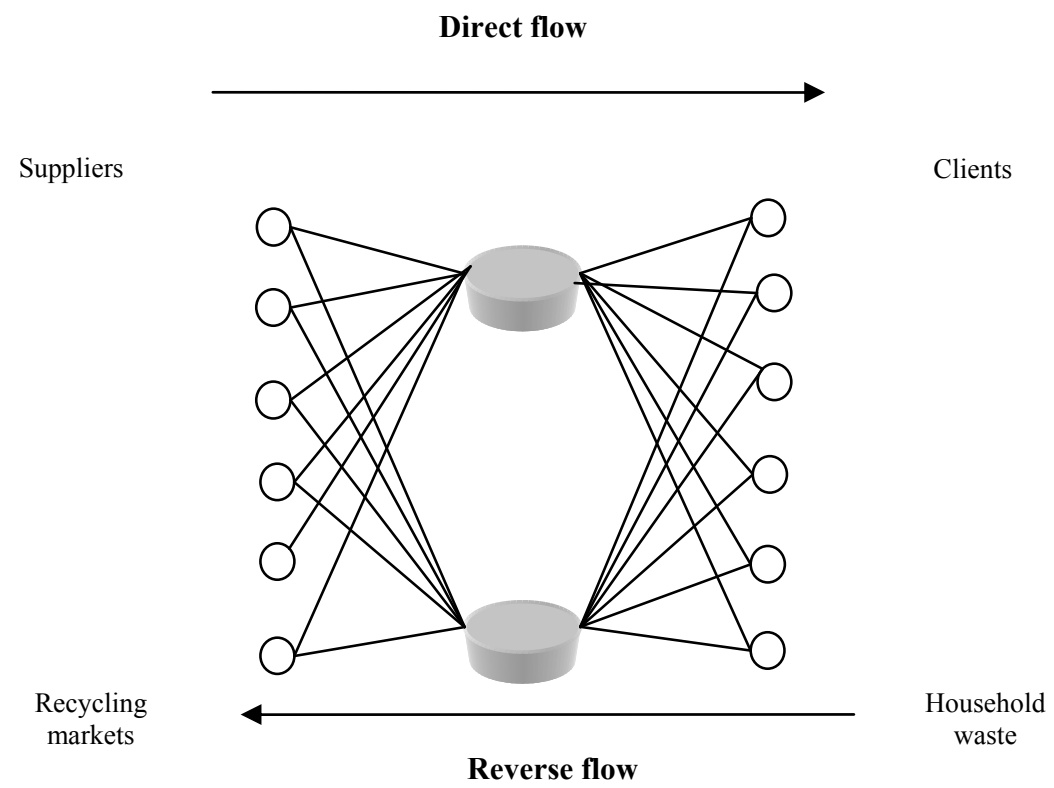

Figure 1- Collection systems, as reverse channels of distribution.

MRF is the abbreviation for materials recovery facility, where products pass through the early stages of the recycling process

Source: Jahre, (1995a)

Economies of scale are closely related to push strategies. This type of strategy is based on demand forecasts horizons established by long term planning. Push strategies are more suitable when opportunities to reduce costs due to economies of scale and uncertainty of demand are low. For certain RLSs, a push strategy demonstrates to be the most appropriate in the collection stage, since the service 
level at this stage is less important than the reduction in costs that results from economies of scale (especially in transports).

Transport costs are especially important for the discussion of economies of scale. There is little margin in the recycling business and product recovery and the costs associated with transportation are comparatively high relative to direct logistics systems (STOCK, 1998). Regarding the possibility of centralizing the operations of recycling or recovery, the author states that although such operations benefit from economies of scale, transportation costs may rise because of the distances between the sources, processing/production and consumer market.

Postponement is a principle that has been applied since 1920's (BOONE et al., 2007). Focusing on marketing channels, Alderson (1950) has introduced the concept of postponement. The concept was originally introduced to reduce the risk and uncertainty costs tied to the differentiation (form, place and time) of goods. Postponement means delaying activities in the supply chain until customer orders are received with the intention of customizing products, as opposed to performing those activities in anticipation of future orders (VAN HOEK, 2001).

For example, in manufacturing postponement, parts are shipped to the distribution centers and the manufacturing is completed on the realization of Customer order. One example to this is the soft drinks industry where the syrup is supplied to bottling facilities where sugar and water are added to obtain the soft drinks (ZINN, BOWERBOX, 1988).

According to Van Hoek (1999), the postponement principle is generic in nature, for being applicable to different parts of a company or supply chain and to be related to different criteria, such as shape and time. In summary, the main purpose of the principle is to reduce risks by keeping products in one place until such time that the request is made or retaining the product without differentiation until the last possible location in the distribution channel.

The postponement principle was studied by Jahre (1995b) with respect to RLSs for household wastes. In this context, postponement means not making any selection of waste collected until the latest possible stage. The gains are in volume, in terms of costs reduction and opportunity to make your selection according to the existing demand by the output fraction. Basically, the postponement principle for 
DOI: 10.14807/ijmp.v5i1.106

RLSs is the same as in a form postponement in production. In his doctoral thesis, Jahre (1995a) arrived at two conclusions regarding household wastes:

- In areas of low population density, recycling programs for household wastes should include fewer fractions and the selection should be done at the source (speculation), while;

- In areas of high population concentration, recycling programs should include several fractions with the separation of waste held in central units of recovery. The first type of structure results in low costs and low service levels, while the second structure achieves high service level and keeps costs down. Therefore, the system choice with respect to the principle adopted (postponement or speculation) should be conducted by the supplier structure.

The principle of economies of scale is of special interest to investigate the performance of reverse logistics systems because the focus on costs is both relevant to the logistics and how to produce. Economies of scale are applicable to a number of areas, of which production was the focus for a long time, both at the level of corporations as at the level of chains.

With respect to the postponement principle, a basic point is the trade-off between risk reduction through the postponement of irreversible operations until the point where customer demand is known and costs reduction happen through, for example, economies of scale.

\section{REVERSE LOGISTICS SYSTEMS AND RETURNS MANAGEMENT}

A reverse logistics system (RLS) is a system that involves all actors, their activities and relationship involved in the process of recovering goods or the value of end-of-life products (FREIRES, GUEDES, 2008). Since RLS is a relatively new area of investigation and is rather practical, other terms can be found in literature, such as: logistics of return, inverse logistics, and backward logistics distribution. All these expressions are almost the same.

The effectiveness and efficiency of such systems is usually evaluated in terms of costs due to the fact that little research has been done in this field. The interest for RLSs is partly due to the pressure of new legislations, which have been forcing the producers to be responsible for the collection and final destiny of their products. Recent developments demonstrate that legislation and its consequences have 
grown, particularly regarding end-of-life (EOL) vehicles, Waste Electrical and Electronic equipment (WEEE) and product's packaging.

Returns management may be defined as the design, control, and operation of a system to maximize value creation over the entire life cycle of a product with the dynamic recovery of value from different types and volumes of returns over time (GUIDE, VAN WASSENHOVE, 2006). This is clearly a business definition. A decade ago, the definition given would have been operational and technical.

Product returns are an increasing concern to industry. Even so, only a small percentage of the value is being recovered. Companies still view product recovery activities as a problem, and this prevents them from identifying potential value creation activities. Hewlett- Packard estimates that returns cost them as much as $2 \%$ of total outbound sales. Less than half of the value of those product returns is being recovered. To make matters even worse, personal computer manufacturers have short life-cycle products that can lose $1 \%$ of their value per week and have high return rates (GUIDE, VAN WASSENHOVE, 2006).

Products, components, materials and equipment can pace a reverse flow in their supply chains. For some time we became familiar with products that are rebuilt during its manufacturing process due to the unsatisfactory aspects of quality. Defective products can be discovered after its entry into the supply chain, resulting in a withdrawal of this product at a later point in its supply chain (Ex: Recall of damaged vehicles). At this stage there are more actors involved in the chain with reverse flow. Business processes such as agreements on return versus take back of obsolete products (B2B - business to business) gain importance. Moreover, in the scenario of relationships with consumers (B2C - business to consumer) products may be sent back due to misuse by the customers or gaps in expected quality (DE BRITO, 2004).

A particular situation is electronic commerce, where high percentages of returned products are not a surprise. During its use and still under warranty, these products can be returned to be replaced by others, or being repaired (warranty and return services). Even after its useful life products are to be collected, for example, remanufactured, recycled or incinerated (end-use and end of life). At this point the question related to the environmental impact must be taken into account, especially in Europe, where environmental issues are in greater evidence. In conclusion, 
products can reverse its direction in the supply chain for a variety of reasons (DEKKER, VANDER LAAN, 2002).

Even in the event that remanufacturing is technically achievable, the potential value recovery must surpass the costs of recovery processes. This is a necessary but not sufficient condition. To make remanufacturing economically attractive, one also needs adequate quantities of used products of the right quality and price, at the right time, as well as a market for the recovered products. In other words, one needs to go far beyond the technical and operational boundaries and take a global business process perspective (GUIDE, VAN WASSENHOVE, 2009).

In short terms, a product is developed and goes into production following its supply chain with the purpose of reaching a customer. However, at any time, the product may return to the supply chain. At this time, the supply chain also embodies activities related to the recovery/collection processes. This is called the Closed Loop of Supply Chain. This designation highlights the possible integration of forward and reverse logistics flows.

\section{METHODOLOGY}

In contrast to quantitative research, which takes a phenomenon to analyze its components, giving rise to the variables of the study, qualitative research seeks to clarify how all the parts operate to form a whole. In this research paper is adopted a qualitative approach, where the researcher is the main tool for collecting and analyzing data. Overall a qualitative study is very descriptive, being developed by the reason that the existing theories are not sufficient to adequately explain the phenomenon in question. The purpose of a qualitative study is not to test theories. So there are no research hypotheses to be deduced from the theory (MERRIAM, 1998).

Among the different visions of the world, this study is located in the interpretative paradigm, and is based on the vision that the events in the social reality do not exist in any fixed direction, but are equivalent to the product of the subjective and interpretative experiences of people. Society is conceived from the perspective of the participant and not that of the observer. Following this orientation, we are able to understand the process by which multiple shared realities are built, kept and modified. Science is conceived as a network of language games, based on concepts 
and rules subjectively determined, created and followed by scientists (STRAUSS and CORBIN, 1998).

From a subjective vision of the reality, the study follows qualitative methods. This, according to Yin (2009), is not a particular set of techniques, but a proposal approach, for the study of a social phenomenon. According to Merriam (1998), the philosophical assumption whereupon all types of qualitative methods are based is the vision that reality is created by individuals interacting with their social worlds. The author adds that investigations following this orientation are interested in understanding the meaning invented by people. This approach tries to understand how individuals live and experience their world.

In contrast with a quantitative inquiry (which takes a phenomenon and analyzes its components), the qualitative investigation seeks to clarify the way individual parts of a system operate to form "the whole". Within this context, the investigator constitutes the main instrument of collection and analysis of data. In a general way a qualitative study is sufficiently descriptive, being developed for the reason that existing theories are not adequate enough to explain the phenomenon in question. The aim of a qualitative study is not to test theories. Therefore, there are no hypotheses to be deduced in the theory.

The position adopted in this article is that a description is always sensitive to context, selective and incomplete, being, therefore, revocable. A description never tells all that can be said about an effort, a per-son, an object or an event. In principle, it is possible to argue against a certain description, pointing out other characteristics from the situation in question. Moreover, when executing the descriptive task, the investigator has an intention and prioritizes what he considers important, in regards to the investigated phenomenon (STRAUSS and CORBIN, 1998).

Merriam (1998) states that the project of a qualitative study is emerging. That is, normally, the investigator does not know beforehand, all of the players that are going to be interviewed, nor all the questions to be asked. On the basis of his intuition the investigator directs his attention to certain segments of data.

In this perspective, this study includes two case studies, one conducted in Portugal and the other in Brazil. Although dealing with the same aspect (RLSs for 
scraptires) the realities of the two cases are different, and the data collection was done in different periods.

The data used is characterized by a variety of qualitative and quantitative data, extracted from primary as well as secondary sources. Based on interviews, the primary data collection procedure is similar to that of the two case-studies (which are the basis of this paper) in terms of preparation of respondents, documentation and verification of the collected data.

Secondary data was captured from observations, companies' information (printed) and internal data collected for other purposes (production volumes, transport volumes and suppliers). The qualitative methodology and quantitative data was combined to discuss the main results of this paper. Table 1 presents a summary of the characteristics of the data sets adopted in this study.

Table 1 - Data Used in this Study

\begin{tabular}{|c|l|l|}
\hline Nature of Data & \multicolumn{1}{c|}{ Qualitative } & \multicolumn{1}{c|}{ Quantitative } \\
\hline Primary & $\begin{array}{l}\text { Descriptions of processes and relationships } \\
\text { Opinions of experts } \\
\text { Interviews } \\
\text { Visits in company } \\
\text { Photos }\end{array}$ & $\begin{array}{l}\text { Weekly processed volumes } \\
\text { Weekly exchanged volumes } \\
\text { Weekly number of truck loads }\end{array}$ \\
\hline Secondary & $\begin{array}{l}\text { Processed contracts } \\
\text { Companies'information from internet } \\
\text { Printed documents } \\
\text { Brochures and catalogues } \\
\text { Videos and softwares }\end{array}$ & $\begin{array}{l}\text { Financial Data } \\
\text { Production and planning reports } \\
\text { Material flows reports }\end{array}$ \\
\hline
\end{tabular}

In a global way, this article aims to provide an understanding of RLSs to generate knowledge of practical and theoretical character. Starting from a generic model of circular flow of materials (Figure 2), the system studied is positioned between the final consumer and the traditional or direct supply chain. 


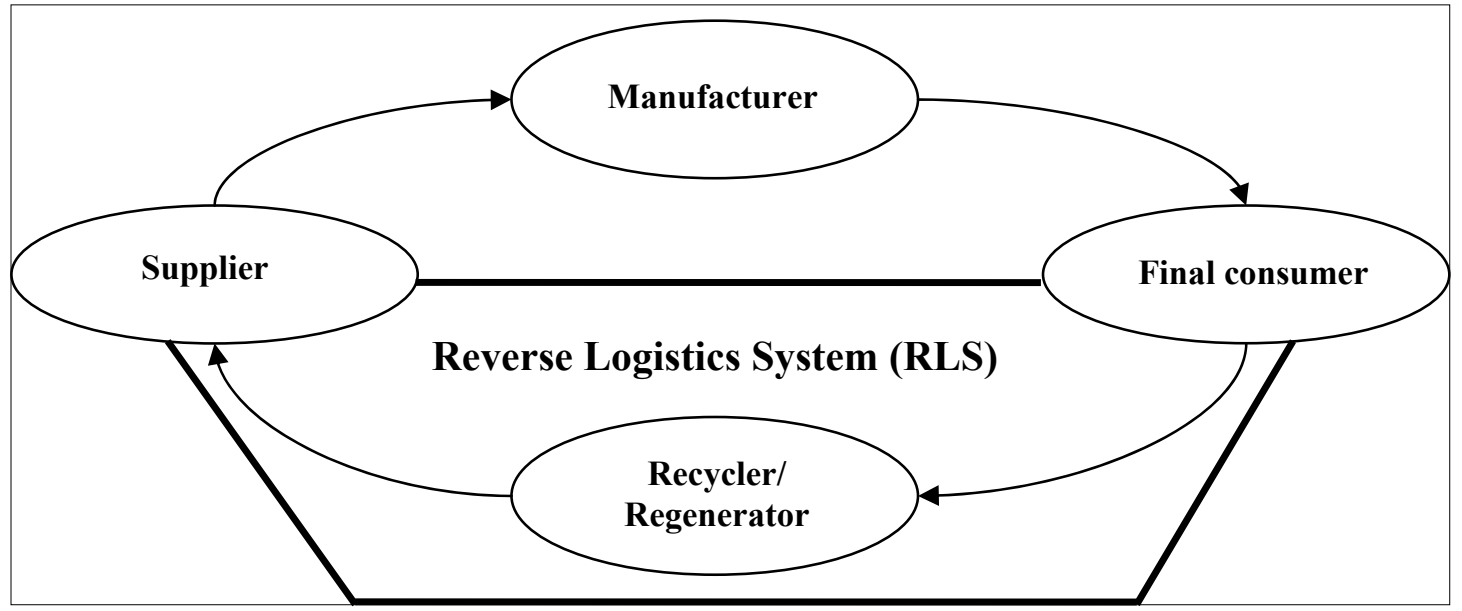

Figure 2 - The generic model and a simplified circular flow of materials and positioning of the reverse logistics system (RLS).

The RLS presented in the previous figure can be broken into several players and their relationships, leading to a chain. The studied system is divided into two phases or subsystems: collection system and post-collection system. It will be studied the connections or relationships with a focus on recycler or first order regenerator, decomposing the RLS in two subsystems (Fig. 3).

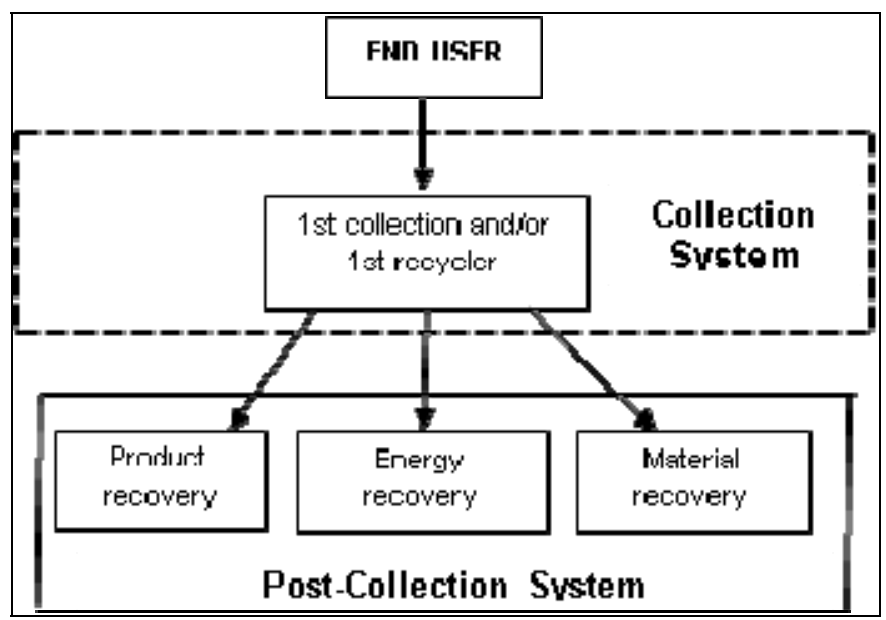

Figure 3 - The RLS studied and their two phases or sub-system: collection and post collection.

The post-collection system can end up with a raw material producer, a manufacturer of final product (if parts are reused), an energy exploiter (fractions of a product used as fuel) or other recycler. The post-collection system starts after the selection and removal of products to be recycled. After these processes, postcollection system is treated as a regular supply chain.

The position adopted in this investigation is that a description is always context-sensitive, selective and incomplete, and therefore revocable. A description 
never exhausts all that can be said about an action, person, object or event. In principle, one can argue against a particular description, pointing out other features of the situation in question. Furthermore, when performing the task description, the investigator has a purpose and prioritizes what you consider important in relation to the investigated phenomenon (STRAUSS, CORBIN, 1998).

\section{CASE STUDIES}

Within this context, the research presented includes two case studies carried out in Portugal and Brazil. After searching for information regarding RLSs for scraptires, these cases were chosen for the availability of data collection and because their reverse logistics systems perfectly fit this research. Both cases follow the same logic of data collection. Observations were made both structured and unstructured, as well as interviews with those involved in the system to obtain answers to research questions. Besides the interviews, photos and notes of observations were also used as primary data. The secondary data used were mainly printed information and internal documents of the companies for other purposes (processed volumes, transported volumes). Hereafter are presented the case studies and their respective RLSs.

The first case study ("Tire Management Company - Valorpneu") sought to describe the implemented management system of end of life tires in Portugal. This system is basically constituted by an entity (Valorpneu) that centralizes the management, a network of waste tires collectors, a recycler (Recipneu) and a final customer (Recipav). Figure 4 presents a description of this system with the presentation of the actors involved. All these actors and their roles within the system are described below.

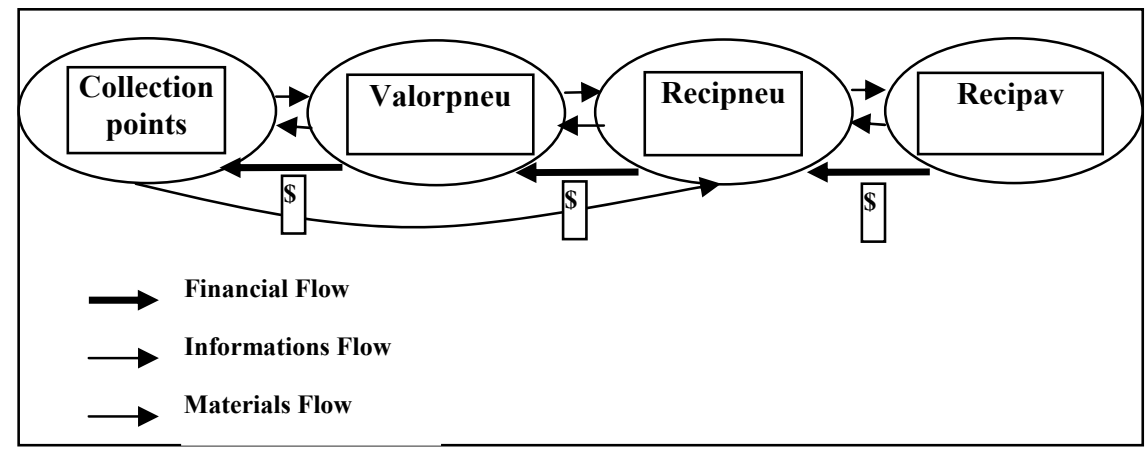

Figure 4 - The reverse logistic system of Valorpneu.

The features of this first case differ from the second one cause its management systems (collection and post-collection) is centered on an entity that 
was formed by the initiative of manufacturers and importers of tires. The fund manager acts as a regulatory system, in other words, it controls the amounts of tires received (delivered by collection points) according to the needs of the recycling companies (Recipneu and Recipav).

The second case was developed in Brazil, where he addressed the reverse logistics system for waste tires, involving a company that makes tire retreading (Bscolway) and an oil exploration company (Petrobras). Besides these two main actors, the case also investigated the role of supporting actors (business associations, collectors cooperatives, chambers and state government). Figure 5 shows a schematic of the system and the actors involved. The data described below were obtained through interviews and observations conducted in the company's Petrobras and BScolway.

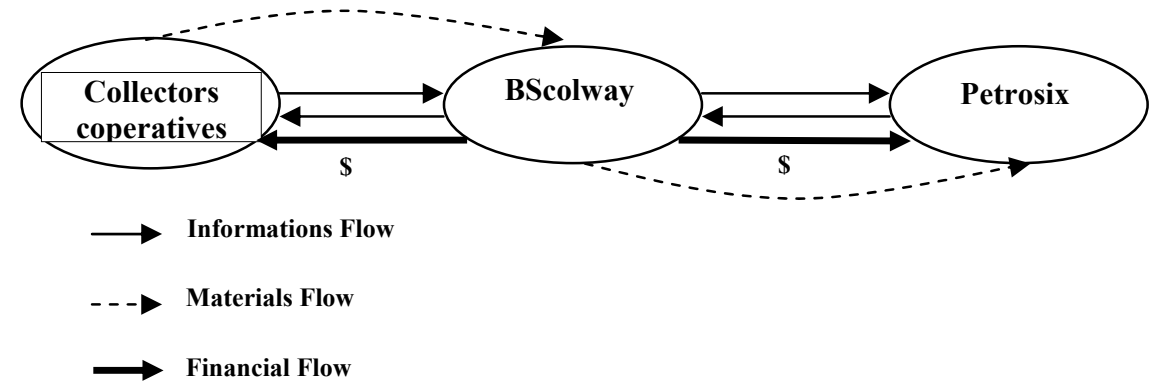

Figure 5 - The reverse logistic system Paraná Running Clean Program.

The purpose of this case study was to obtain the prospect of a revaluation of experience with tires in a developing country and describe the relationships between the actors investigated. We chose to study a developing country, given that the economic and social reality is very different from Europe. Consequently, the motives (reasons, forces, drivers) that lead to recycling of tires are different from Europeans.

The characteristic of the data was mostly qualitative, seeking to describe and understand the activities within the inter-organizational relationships. Primary data were collected through visits to companies and personal interviews (structured and semi-structured). The visits were always accompanied by middle managers or directors. Prior to the semi-structured interviews, a script was sent via e-mail and all interviews were recorded. As supplements to the information provided during interviews and visits, it were also collected secondary data (company documents, booklets, videos and electronic information) in order to gain a greater understanding of each actor within the system. 
DOI: 10.14807/ijmp.v5i1.106

\section{DATA ANALYSIS}

Before starting the discussion on economies of scale in RLSs scraptires, it will be taken the example of this principle application to another product, the paper. Paper is usually collected by compactor trucks. This is an important aspect for achieving efficiency in transportation to the paper recycling facility.

The use of compactor trucks is a clear example of how to increase the effectiveness and efficiency of logistics. Without the compression of the paper, the volume filled by truck would be underweighted. A high utilization of resources is achieved through compression of paper transported, because the load capacity with respect to weight is better exploited, leading to greater efficiency. Compression has also positive impact on the effectiveness, in terms of cost, because of the fact that fewer trucks can transport the same quantity of products.

Another way to make transport more efficient is to collect only a specific category of paper during the same trip. Although sometimes mean a greater number of stops per trip, less effort also entails selection of the paper when it is received at the recycling facility. In line with Jahre (1995a), this collection method was more efficient than the collection of all grades of paper during the same trip.

For the cases studied, economies of scale were applied deliberately for the process of scraptires recycling. Despite the legal issues, there is an expectation that economies of scope should be adopted at a multinational level, or even global to the issue of scraptire recycling. In a way, this has already been checked when -rich tires countries export waste tires to developing countries.

With regard to transport, economies of scale were applied in the form of higher utilization rates in order to increase the efficiency of reverse logistics system capacity. This also had a positive impact on efficiency and cost of the system. However, it also meant a decrease in the frequency of collection of waste tires, both in relation to the collection system and the post-collection. A possible solution would be to increase the quantities of materials operators, not yet in a fully consolidated basis for the emerging market for waste tires.

There is an expected increase in the number of companies that use fractionated materials (rubber, steel and fiber) out of waste tires as raw materials for other products. It is expected that the demand for waste tire will increase due to 
DOI: 10.14807/ijmp.v5i1.106

industries that use this product as an alternative energy to diesel. In particular, there is already a growing demand from cement factories, to use waste tires as fuel for their ovens.

Related to speculation, in opposition to the conclusions of Jahre (1995a), their adoption was only observed in the stage of collection, still in a much reduced scale. On the other way, in all cases investigated it was identified the practice of postponement. This means that once the tires leave the waste-collection point, is not carried out any kind of selection until reaching the recycling units. This is more an effect of low volumes of product than a deliberate strategy of postponement. What will happen when volumes begin to grow is a point to consider in future research.

In the cases investigated it is clear that economies of scale are adopted with respect to transport and recycling. With regard to the practice of postponement, this was identified in all cases.

In case 2, the collection of scraptires is performed by the distributor of retread plant BScolway from its various retailers, this leads to the coordination of collection activities with deliveries to retail outlets. Transport in the collection phase of this RLS is an example of closed-loop system. Economies of scale in the system are obtained in the logistic activities through the consolidation of the selection process and a good ability to coordinate transportation.

Regarded to recycling processes, BScolway, considered a centralized structure as the best option in terms of achieving economies of scale. The efficiency of the recycling process depends largely on the quality and quantity of waste tires to be processed. Thus, a centralized structure enables the processing of high volumes, reaching economies of scale turning the system more effective and efficient.

The case of Valorpneu has some differences from the BScolway. The collection system for waste tire is driven by 27 collection points scattered through Portuguese territory. As previously described these points are represented by waste treatment municipal companies', recycling companies, scrap tires and tire recycling operators. These companies act as "lungs" in the supply chain of waste tires, since they hold up stocks to a certain volume before notifying Valorpneu to collect them. At this point, RLS management of Valorpneu is more complex than the BScolway, as composed of a greater diversity of collection points. However, in terms of spatial 
coverage, BScolway RLS management covers a territory of approximately 450,000 $\mathrm{km} 2$, representing about five times the Portuguese territory.

After the collection of scraptire from the collection points, Valorpneu starts to manage the transport to the recycling company Recipneu. Transport is performed by more than one company selected by Valorpneu. Unlike BScolway the Valorpneu contracts specific companies for the transportation of waste tires, and does not constitute a closed loop as in the situation of BScolway. The recycling system is also centralized in a single actor, Recipneu.

Note that when considering the aspects of performance (effectiveness and efficiency), the reverse logistics system cannot be separated from the recycling process. Several players expressed this aspect through the empirical descriptions. It was also shown that different actors with different specialties perceived the relationship between the principle of economies of scale and performance differently. For example, the end customers (Petrobras and Recipav) of the two systems investigated gave importance to the economies of scale in transport, not considering the same extent for the recycling process.

The definition of time schedule for deliveries was affirmed by the two recyclers (BScolway and Recipneu) as a need for good system performance. The Recipneu receives waste tires at intervals of at least 30 minutes, according to the schedule agreed with Valorpneu. This time period was determined by Recipneu as the maximum time not to form lines of trucks in the recycling unit. BScolway receives waste tires according to a scale set in conjunction with its dealers and only full loads are accepted.

The reason given for adopting such strict requirements is due to the need to achieve an efficient supply of materials. Beyond this, respondents also justified for security reasons the desire to keep download times short (maximum 30 minutes). Several vehicles circulating in the recycling unit means an increased risk of accidents.

Coordination between the distribution systems and direct RLSs is possible in situations where the recycling or reprocessing units are close to units of direct distribution. Gains in efficiency can be obtained in terms of transport capacity, and the effectiveness of RLSs. However, this is an issue that emerged during the 
research process and was not analyzed in the same level of detail as the issues related to economies of scale and postponement, which becomes a suggestion for future deeper investigations. This type of coordination was observed in the collection phase of the RLS program "Clean Running Paraná", where BScolway used its distribution structure to collect the waste tires deposited in their stores. According to what has been stated in this paper, the coordination between the direct and reverse flow is a typical case of a closed circuit. The influence of structural aspects of the effectiveness and efficiency of RLSs are summarized in Figure 6.

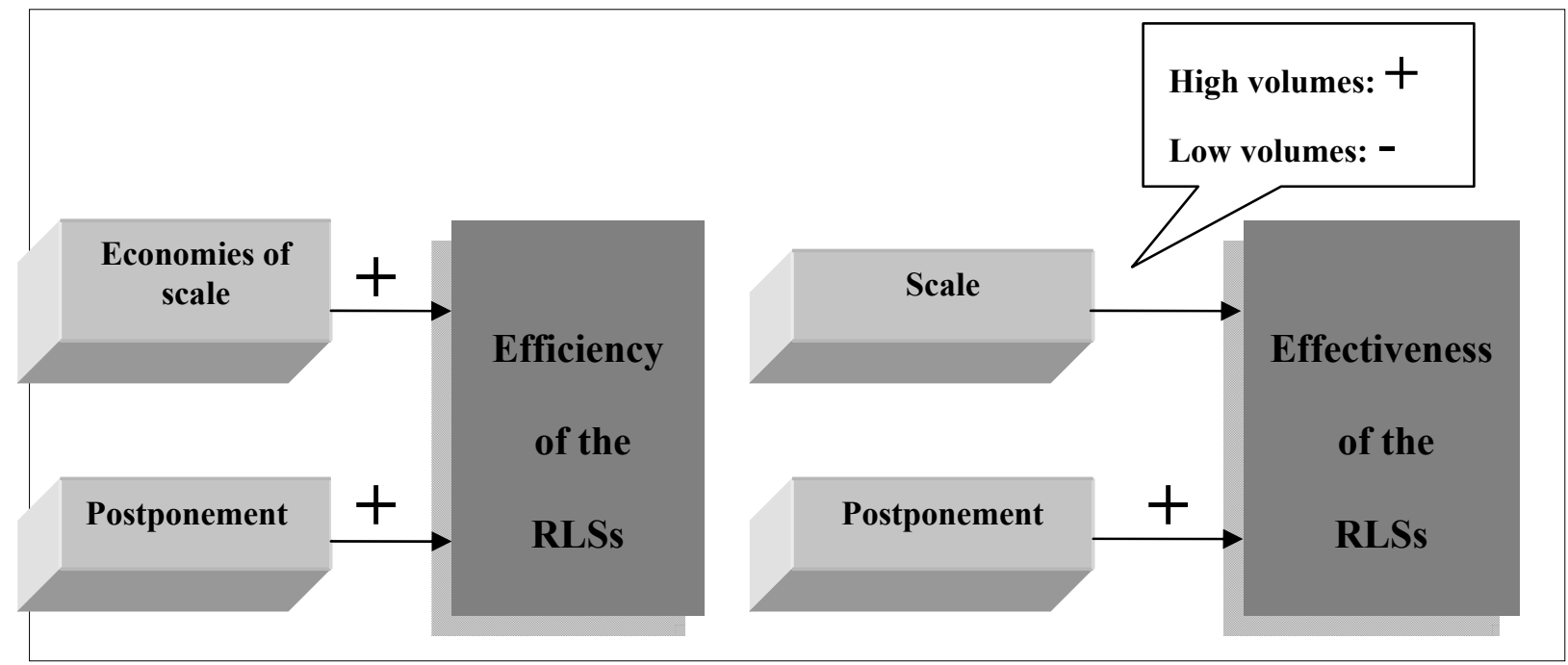

Figure 6 - Influence of structure on performance (efficiency and effectiveness) of RLSs in terms of indicators. The +/- signs indicate whether the relationship is positive or negative.

The volumes of scraptires are still quite small and irregular to talk about logistics structures actually consolidated. However, it is expected (in both Brazil and Portugal) a growth in a more regular supply of waste tires. The greatest uncertainty regarding the supply pointed to is also the behavior of final consumers.

\section{CONCLUSIONS}

According to the suggestions of Stock (1998) for the case of paper recycling, economies of scale are an opportunity available due to higher volumes and market maturity. The consequence of this principle for the scraptires case is a high efficiency-related costs, system capacity and service level.

The efficiency of RLSs is aided by economies of scale, in large part this is due to the fact that high rates of use are achieved, which is related to the efficiency in terms of capacity. The principle of economies of scale also contributes to the 
increase of efficacy, since it decreases RLSs costs. A negative effect was identified in post-collection system; to obtain satisfactory volumes for economies of scale, the frequency of collection of waste tire is low, which reflects as an inefficient level of service to the end customer (paving companies, factories of articles of rubber and cement plants).

Despite the fact that demand for scraptires is still small, the practice of postponement was observed in both cases investigated. According to what was previously expressed in this paper, the postponement means that the various types of tires are transported along the points of collection to the recycling plants, and only there they undergo a selection process.

Postponement practices were identified in the collection system of scrapires, however the highest reason described for the centralization of the selection process was the desire to achieve economies of scale. It can be argued that the postponement has positive effects on efficiency, by increasing the system capacity. Due to providing the reduction of logistics costs and indirectly to lead to economies of scale, the postponement has a positive influence on the effectiveness of RLSs.

Finally, there is an influence of the maturity of the market on the economies of scale. In the case of paper recycling, the market is already stabilized (Recycling Forum, 2000). The volumes are high and constant, being of course possible to achieve economies of scale, which is directly opposite to the case of scraptire market.

\section{REFERENCES}

ALDERSON, W. (1950). Marketing efficiency and the principle of postponement. Cost and Profit Outlook, v. 3, p. 15-18.

BOONE, C. A.; CRAIGHEAD, C. W.; HANNA, J. B. (2007). Postponement: an evolving supply chain concept. International Journal of Physical Distribution and Logistics Management, v. 37, n. 8, p. $594-611$

DE BRITO, M. (2004). Managing Reverse Logistics or Reversing Logistics Management? PhD Thesis, Erasmus Research Institute of Management, Erasmus University of Rotterdam, Netherlands.

DEKKER, R.; PORRAS, E. (2005). Controlling Inventories in a Supply Chain: a Case Study. International Journal of Production Economics, v. 94, p. 179-188.

FEITZINGER, E.; LEE, H. L. (1997). Mass customization at Hewlett-Packard: the power of postponement. Harvard Business Review, v. 75, p. 116-121. 
FERGUSON, M; FLEISCHMANN, M; DE SOUZA, G. (2010). Applying Revenue Management to Reverse Supply Chain. Technical Repport, Erasmus Research Institute of Management, Rotterdam, Netherlands.

FREIRES, F. G.; GUEDES, A. P. S. (2008). Power And Trust in Reverse Logistics Systems for Scraptires and its Impact on Performance. Journal of Operations and Supply Chain Management, v. 1, n. 1, p. 57-65.

GALBRETH, M.; BLACKBURN, J. D. (2010). Offshore remanufacturing with variable usable product condition, Decision Sciences, v. 41, n. 1, p. 5-20.

GEYER, R.; VAN WASSENHOV, L.; ATASU, A. (2007). The economics of remanufacturing under limited component durability and finite product life cycles. Management Science, v. 53, n. 1, p. 88-100.

GUIDE, Jr., D.; VAN WASSENHOVE, L. N. (2006) Closed- loop supply chains. Special Issue, Production \& Operational Management, v. 15, n. (3\&4).

GUIDE, Jr., D.; VAN WASSENHOVE, L. N. (2009) The evolution of closedloop supply chain research. Operations Research, v. 57, n. 1, p. 10-18.

HARRINGTON, J. (1993). Business Process Improvement: The Breaktrhough Strategy for Total Quality, Productivity and Competitiveness. McGraw-Hill, New York ( $2^{\text {nd }}$ edition).

JAHRE, M. (1995a), Logistics Systems for Recycling- Efficient Collection of Household Waste. Doctoral Thesis, Department of Logistics and Transportation, Chalmers University of Technology, Sweden.

JAHRE, M. (1995b), Household waste collection as Reverse Channels - a theoretical perspective. International Journal of Physical Distribution and Logistics Management, v. 25, n. 2, p. 39-55.

JAHRE, M., VIRUM, H. (1993), Comparing systems for collection, reuse and recycling in the case of electronics, The First International Working Seminar on Reuse, Eindhoven (Netherlands).

MERRIAM, S. (1998). Qualitative research and case study applications in education. Jossey-Bass, San Francisco ( $3^{\text {rd }}$ edition).

NEELY, A. GREGORY, M. e PLATTS, K. (1995). Performance Measurement System Design. International Journal of Operations \& Production Management, v. 15, n. 4, p. 80-96.

PAGH, J., \& COOPER, M. (1998). Supply Chain Postponement and Speculation Strategies: How to Choose the Right Strategy. Journal of Business Logistics, v. 19, n. 2, p. 13-33.

STEFAN HOLMBERG, (2000) A systems perspective on supply chain measurements, International Journal of Physical Distribution \& Logistics Management, v. 30, n. 10, p. 847 - 868

STOCK, J. R. (1998). Development and Implementation of Reverse Logistics Programs. Oak Brook: Council of Logistics Management.

STRAUSS, A., \& CORBIN, J. (1998), Basics of qualitative research: techniques and procedures for developing grounded theory. Sage Publications, San Francisco $\left(2^{\text {nd }}\right.$ edition $)$. 
VAN HOEK, R. (1999). From reversed logistics to green supply chains. Supply Chain Management, v. 4, n. 3, p. 129-134.

VAN HOEK, R. (2001). The rediscovery of postponement: a literature review and directions for research. Journal of Operations Management, v.19, p. 161-184.

VAN HOEK, R., COMMANDEUR, H., Vos, B. (1998), Reconfiguring Logistics Systems Through Postponement Strategies. International Journal of Business Logistics, v.19, n. 1, p. 33-54.

YANG, B., YANG, Y. and WIJNGAARD, J. (2007). Postponement: an interorganizational perspective. International Journal of Production Research, v.45, n. 4, p. 971-988.

YIN, R. (2009). Case study research: design and methods. Sage Publications, London ( $4^{\text {th }}$ edition).

ZINN, W. and BOWERBOX, D. (1988). Planning Physical Distribution with the Principle of Postponement. Journal of Business Logistics, v. 9, n. 2, p. 117-136. 